\title{
Políticas Públicas de Turismo: uma análise dos planos nacionais de turismo do Brasil (2003- 2022)
}

\section{Resumo}

Graziele Júnia Pereira Vilela ${ }^{a}$ Helena Araújo Costab

Os Planos Nacionais de Turismo (PNT) são instrumentos de planejamento das políticas públicas que documentam a estratégia, as diretrizes, os programas e as ações para o setor. Este trabalho teve como objetivo realizar uma análise dos PNT que cobrem o período de 2003 a 2022. Assim, o artigo propõe uma visão sistemática acerca de cinco categorias de análise: diagnóstico, objetivos, conjunto de intervenções, continuidade e inovação. Para isso, foi realizada uma pesquisa documental-bibliográfica baseada na consulta aos planos nacionais publicados, com uso de análise de conteúdo. A proposição destas cinco categorias considerou as reflexões dos autores estudados sobre variados aspectos dos PNT. Entre os principais resultados observados, destacam-se seis pontos: falta encadeamento claro entre diagnóstico, objetivos e metas; ausência de padronização na definição dos indicadores e a dificuldade em observar sua evolução; a necessidade de melhor delimitação do escopo de atuação; a ausência de reflexão sobre a execução das intervenções propostas nos planos anteriores e de absorção limitada da inovação nos planos nacionais de turismo brasileiros.

Palavras-chaves: Turismo; Políticas Públicas; Planos Nacionais; Brasil.

\section{Abstract \\ Tourism Public Policies: an analysis of Brazilian national tourism plans (2003-2022)}

The National Tourism Plans are planning's tools of public policies that document the sector's strategy, guidelines, programs and actions. The objective of this paper was to perform a critical analysis of the plans covering the period from 2003 to 2022 . The article proposes a systematic view of five categories of analysis: diagnosis, objectives, overall interventions, continuity and innovation. For this, a documentary-bibliographic research was conducted based on the consultation of the published national plans. And was used content analysis. The proposition of these five categories considered the authors' reflections on various aspects of the plans. Among the main results observed, six points stand out: lack of clear linkage between diagnosis, objectives and goals; lack of standardization in the definition of indicators and the difficulty in observing their evolution; the need for better delimitation of the scope of action; the lack of reflection on the implementation of the interventions proposed in the previous plans and the limited absorption of innovation in the Brazilian national tourism plans.

Keywords: Tourism; Public Policies; National Plans; Brazil

a. Mestra em Turismo pelo Centro de Excelência em Turismo da Universidade de Brasília (UnB), Brasília, Distrito Federal, Brasil. E-mail: graziele_junia@yahoo.com.br

b. Doutora em Desenvolvimento Sustentável pelo Centro de Desenvolvimento Sustentável da Universidade de Brasília (UnB). Docente da Faculdade de Administração, Economia, Contabilidade e Políticas Públicas da Universidade de Brasília (UnB), Brasília, Distrito Federal, Brasil. E-mail: helenacosta@unb.br 


\section{Resumen}

Políticas Públicas de Turismo: un análisis de los planes nacionales de turismo de Brasil (2003-2022)

Los Planes Nacionales de Turismo son herramientas de planificación de políticas públicas que documentan la estrategia, directrices, programas y acciones del sector. El objetivo de este trabajo fue realizar un análisis crítico de los planes qué cubren el período de 2003 a 2022. El artículo propone una visión sistemática de cinco categorías de análisis: diagnóstico, objetivos, en general intervenciones, continuidad e innovación. Para ello, se realizó una investigación documental-bibliográfica basada en la consulta de los planes nacionales publicados. Y se realizó análisis de contenido. La propuesta de estas cinco categorías consideró las reflexiones de los autores sobre diversos aspectos de los planes. Entre los principales resultados observados, destacan seis puntos: falta de un vínculo claro entre el diagnóstico, los objetivos y las metas; falta de estandarización en la definición de indicadores y la dificultad de observar su evolución; la necesidad de una mejor delimitación del alcance de la acción; la falta de reflexión sobre la implementación de las intervenciones propuestas en los planes anteriores y la absorción limitada de innovación en los planes nacionales de turismo de Brasil.

Palabras clave: Turismo; Políticas Públicas; Planes Nacionales; Brasil.

\section{INTRODUÇÃo}

As políticas públicas (PP) podem ser entendidas como o fluxo de decisões e o conjunto de ações concretas realizadas pelo poder público para alcançar os resultados desejáveis para as demandas da sociedade (Saravia, 2006). Elas podem ser expressas por diversos instrumentos, incluindo os planos setoriais. Neste trabalho, o interesse recai sobre as políticas públicas e planos nacionais de turismo (PNT) brasileiros.

A intervenção da administração pública em determinado tema se dá por meio das PP. No turismo são esperados os papéis de coordenação e planejamento, legislação e regulação, promoção e incentivo a empreendimentos, inclusão social e proteção dos interesses da comunidade anfitriã (Hall, 2001). Para cada um, almeja-se que as políticas públicas de turismo (PPTur) estabeleçam diretrizes claras e mensuráveis, de modo participativo, e que sejam comunicadas aos atores ligados à atividade.

Em um breve resgate histórico internacional, é possível observar que as PPTur passaram a ser consideradas no arcabouço de atuação governamental apenas na década de 1970. Neste período o turismo começou a ser visto como algo que poderia gerar impactos sobre a sociedade, a economia e o meio ambiente (Hall \& Jenkins, 2004). Nessa perspectiva, conforme aponta González (2014), o turismo passou a ser considerado como objeto de PP em função de se valer de bens públicos e de uso comum, assim como por estes impactos que ele poderia gerar.

No Brasil, há registros da formulação de cinco planos nacionais de turismo (PNT), sendo referentes aos períodos: 1992-1996; 2003-2007, 2007-2010; 2013-2016 e, por fim, 2018-2022. Este trabalho foi, então, orientado pela seguinte pergunta: como esses planos avançaram e se articularam entre si? A partir disso, o artigo tem o objetivo de realizar uma análise sistemática acerca dos planos nacionais de turismo brasileiros. Para a discussão, foram propostas cinco categorias: diagnóstico, objetivos, conjunto de intervenções, continuidade e inovação. 
Ressalta-se que o PNT 1992-1996 será excluído, em razão de sua não implementação. Portanto, a análise cobrirá os planos relativos ao período de 2003 a 2022.

As PPTur brasileiras são relativamente recentes. Como explicam Candiotto e Bonetti (2015), apenas a partir da década de 1990 é que o setor passa a ser exaltado como um vetor de desenvolvimento. Há indicativos de que os estudos ainda são pontuais, bem como são poucos os grupos de pesquisas dedicados ao tema específico das políticas públicas em turismo (Hall \& Jenkins, 2004; Lohmann \& Panosso Netto, 2008).

Apesar desta escassez, encontram-se autores, como Sansolo e Cruz (2003), Noia et al. (2007), Moya e Dias (2008), Kanitz et al. (2009), Kanitz et al. (2010), Sanchoe Irving(2010), Souza eFerreira(2011); Nascimento(2013); Lemos(2013), que se propõem a discutir as PPTur com foco nos planos de turismo brasileiros. Os citados autores aportaram reflexões acerca dos planos sob distintas perspectivas. Todavia, identificou-se a carência de uma visão longitudinal e comparativa entre os planos. Os autores a oferecerem contribuições neste sentido foram Pimentel et al. (2011) ao identificarem as cinco "vidas" da agenda pública de turismo no período de 1930 a 2010. Os planos, aqui analisados, se concentram na última vida, os anos 2000, sendo que os dois últimos adentram pelas décadas de 2010 e 2020.

As contribuições esperadas deste trabalho, portanto, podem ser vistas do ponto de vista acadêmico e de gestão. Academicamente, o presente artigo pretende oferecer uma perspectiva dos ciclos dos quatro PNT e propor uma análise comparativa e longitudinal, por meio das categorias pré-estabelecidas. Do ponto de vista de gestão, pode oferecer insumos para melhorias em futuras versões dos planos nacionais de turismo.

A estrutura do artigo foi organizada da seguinte maneira: seguindo-se a esta introdução, apresenta-se o referencial teórico sobre os principais constructos da pesquisa. Então, são esclarecidos os aspectos metodológicos do estudo e apresentados os resultados e a análise. Por fim, apresentam-se as considerações finais e as limitações do estudo, ao lado das sugestões para estudos futuros.

\section{POLÍtICAS PÚBLICAS: CONCEITOS E SUAS CARACTERÍSTICAS NA REALIDADE BRASILEIRA}

O olhar para políticas públicas, enquanto ciência, tem origem nos Estados Unidos, em meados do século XX (Pereira, 1999; Souza, 2006), quando as diversas publicações científicas tinham como foco a ação do governo. Já na Europa, o objeto de estudo era o papel do Estado e de suas instituições. A partir desses marcos, diversos pensadores começaram a busca pela conceituação do termo, pela definição do escopo, pela compreensão da dinâmica, entre outros aspectos (Souza, 2006).

Este artigo adota o entendimento de Saravia (2006) das PP como o fluxo de decisões para a tomada de medidas concretas, de caráter público e participativo, destinado a modificar determinada realidade eatender as demandas da sociedade. Sem olvidar que as PP, incluindo as de turismo, carregam em si as disputas de visão de mundo e de entendimentos ideológicos, e que ao redor delas há embates entre distintos grupos pelo poder decisório (Kingdon, 1995; Gelinski \& Seibel, 2008; 
Lanzarini \& Barreto, 2014). A composição das políticas públicas, portanto, se faz em uma arena de múltiplos interesses e forças.

As políticas públicas precisam ser traduzidas em dispositivos e instrumentos concretos, como normas, previsões de orçamento, programas, linhas de ação e planos (Dias \& Matos, 2012). Hall e Jenkins (2004) complementam que para uma política ser considerada como pública, no mínimo, precisa ser processada por agências públicas, mesmo que esse processamento envolva apenas uma autorização ou uma ratificação. Têm-se, então, três elementos que ajudam na conceituação: a) objeto público (Saravia, 2006; Souza, 2006), b) tradução da intenção em dispositivos e instrumentos concretos (Dias \& Matos, 2012) e c) autorização ou ratificação por agências públicas (Hall \& Jenkins, 2004; Saravia, 2006).

Entre as características esperadas das PP, o Banco Interamericano de Desenvolvimento (BID) (como citado em Dias e Matos, 2012), elenca seis centrais: estabilidade, adaptabilidade, coerência e coordenação, qualidade da implementação e aplicação efetiva, consideração do interesse público e eficiência. A estabilidade e a adaptabilidade, são definidas como a não alteração meramente devido às motivações políticas. As mudanças devem ser gradativas, amparadas pelas realizações das administrações anteriores e passíveis de ajustes na medida em que as circunstâncias se alteram. No Brasil, em contraposição a esta recomendação, conforme alerta Rua (2006), as PP são marcadas pela fragmentação, seja em função da atuação isolada dos diferentes organismos públicos ou pela descontinuidade administrativa.

Por outro lado, em determinadas políticas públicas brasileiras, existe uma característica, em certa medida oposta à fragmentação. É a vulnerabilidade às decisões das administrações anteriores, resultando em mudanças apenas pontuais e, dificilmente estruturais (Rodrigues, 2010), limitando também a inovação contida por elas. Essa reflexão revela a importância, e o desafio, de que as políticas públicas equilibrem a necessidade de continuidade com a de inovação.

Segundo Rua (2006), no que se refere à quarta característica, a qualidade da implementação e da aplicação efetiva, no Brasil há um evidente descolamento entre as etapas de formulação/decisão e implementação. Um dos motivos para essa postura é uma crença equivocada que a formulação é uma etapa mais complexa que a implementação das PP, uma vez que as decisões já foram previamente tomadas. Como resultados, tem-se uma tendência à centralização, baixa autonomia das agências responsáveis pela implementação, um modelo com alta rigidez às necessidades de adaptação e, um consequente, desperdício de recursos.

A atuação do governo no turismo, entre outros objetivos, deveria se dar para definir os papéis dos diferentes atores envolvidos (PEREIRA, 1999; CRUZ, 2000), evitar o desenvolvimento descontrolado motivado apenas pelo lucro (PEREIRA, 1999) e para amenizar falhas do mercado (HALL, 2001). Entretanto, outra regularidade das PP brasileiras é o descompasso entre as reais necessidades e o planejamento proposto (Rua, 2006), ferindo assim a consideração do interesse público, quinta característica central. Como resultados negativos, este descompasso gera desperdícios financeiros na implementação de PP pouco assertivas, lacunas na participação social, falta de credibilidade no Estado e a frustação da sociedade. Consequentemente, a sexta e última característica central das PP, a eficiência, fica comprometida na realidade brasileira. 


\section{POLÍtICAS PÚBLICAS DE TURISMO E A CRONOLOGIA DOS PLANOS NACIONAIS DE TURISMO BRASILEIROS}

Ao analisar a atuação governamental nos últimos sessenta anos, constata-se que os objetivos e os focos das PPTur mudam ao longo do tempo (González, 2014). Ainda assim, de acordo a autora, essa atuação tende a se dar ao redor de três principais âmbitos: turistas, empresas turísticas e destinos turísticos.

Quanto aos turistas, a atuação pública tem sido centrada na facilitação do deslocamento e na proteção. Já a relação com as empresas passa pelo apoio à criação e à inovação inerentes ao turismo. As primeiras empresas beneficiadas por esse apoio foram os meios de hospedagem, com a formação de trabalhadores, linhas de financiamento, legislação específica e qualidade da oferta (González, 2014). Por sua vez, conforme explica González (2014), a ação que mais demandou envolvimento do poder público nos destinos turísticos foi a promoção. Na sequência, aparecem os investimentos em infraestrutura, processos de renovação de destinos já consolidados e estimulo à cooperação entre os diferentes setores.

Geralmente, as citadas diretrizes das políticas públicas de turismo tendem a ser expressas e organizadas em planos. O Plano de Turismo é visto como o documento estratégico, baseado em etapas prévias de gestão e conhecimento, que expressa as PPTur. Pode ser organizado em programas, projetos e ações com as respectivas previsões de recurso, e que se desenvolve de acordo com o consenso da maioria dos agentes do setor (Fayos-Solá et al., 2012). 0 plano pode ser elaborado nas esferas nacionais, regionais, estaduais e municipais.

0 presente artigo concentrará sua análise nos planos elaborados na esfera nacional, compreendendo o período de 2003 a 2022. Os anos 2000, que concentram dois Planos Nacionais de Turismo - PNT, têm como marcos a criação do Ministério do Turismo (MTUR) e a ampliação do Conselho Nacional de Turismo (CNT), que passa a ser vinculado ao órgão recém-criado e que, posteriormente, integra o Sistema Nacional de Turismo. Outras ações de destaque foram a criação do Programa de Regio00000000000000nalização do Turismo, em substituição ao Programa de Municipalização do Turismo e o lançamento do Programa de Aceleração do Crescimento, considerado como um aliado para o desenvolvimento do turismo (Pimentel et al., 2011; Candiotto \& Bonetti, 2015). Esse contexto indica que muitas ações estruturantes foram propostas. Entretanto, para Candiotto e Bonetti (2015), as mudanças foram mais de caráter normativo do que estrutural e não chegaram a expressar uma Política Nacional de Turismo.

Assim, o primeiro PNT compreende o período de 2003-2007 e corresponde aos primeiros anos do Governo Lula. Ele está estruturado em sete macro programas estratégicos que, por sua vez, resultariam em propostas de ações. As principais bandeiras se concentravam no desenvolvimento econômico sustentável, na inclusão social e na gestão descentralizada (Lanzarini \& Barreto, 2014). Para Noia et al. (2007) a proposta principal do PNT 2003-2007 era a de consolidar o MTUR, que teria o papel de articulador, e focar a atuação da Embratur na promoção do produto turístico brasileiro.

A criação do MTUR e as propostas de estruturas representativas nas diferentes esferas de poder são consideradas como avanços (Sancho \& Irving, 2010). Entretanto, Cruz e Sansolo (2003), Candiotto e Bonetti (2015) afirmam que faltou clareza sobre qual PPTur estava por trás do PNT, ou se havia alguma, já que 
o governo se apressou apenas em elaborar um plano de trabalho. Não houve, assim, uma definição de uma macro estratégia. Noia et al. (2007) criticaram o diagnóstico do PNT 2003-2007 que, segundo os autores, era superficial. Além da ausência de dados fundamentais, como o PIB do turismo brasileiro, o diagnóstico considera o país como um todo, contrariando a lógica de regionalização proposta.

Por sua vez, o PNT 2007-2010 é amparado na continuidade da gestão federal. Consoante ao disposto por Lanzarini e Barreto (2014), seu slogan, "Uma Viagem de Inclusão", traz a proposta de integração regional, capaz de criar alternativas turísticas, ampliando assim a oferta em territórios onde o turismo é considerado como incipiente. E o olhar também é voltado para o mercado global, no intuito de internacionalizar os destinos. A gestão descentralizada, abordada no plano anterior, aparece de forma destacada. Nele, reforça-se os papéis do Fórum Nacional dos Secretários e Dirigentes Estaduais de Turismo (FORNATUR) e do CNT (MTUR, 2007). Diferentemente de seu antecessor, o PNT 2007-2010 apresenta um detalhamento mais completo sobre os oito macroprogramas e os respectivos programas. Ainda, aborda temáticas que não estavam previstas anteriormente, tal como a acessibilidade.

Já o PNT 2013-2016, lançado após uma lacuna de três anos, corresponde ao primeiro mandato do Governo Dilma. 0 discurso público passa a ser "o turismo fazendo muito mais pelo Brasil' cujo ideário de desenvolvimento continua a demarcar uma atividade que amplia suas fronteiras pelo aumento de consumo e expansão de infraestrutura" (Lanzarini \& Barreto, 2014, p. 207). Este PNT tem como principal diretriz o investimento em infraestrutura de acesso e esportiva, em função dos megaeventos que estavam por vir. Há de se ressaltar que esta proposta também foi questionada por manifestações populares realizadas contra a Copa do Mundo de 2014.

Em março de 2018, foi lançado o PNT 2018-2022, no Governo Temer, que teve como mote "Mais Emprego e Renda para o Brasil" e marcou os 15 anos de criação do Ministério do Turismo. Ele foi publicado um ano após o pacote de medidas Brasil+Turismo, documento que buscava elencar ações consideradas como "imprescindíveis e urgentes" para o turismo nacional. 0 plano foi estruturado em quatro grandes seções: Diagnóstico do turismo no mundo e no Brasil; Metas Globais para o Turismo no Brasil; Diretrizes e Linhas de Atuação.

A análise aqui proposta foi fundamentada em aspectos relacionados à formulação do plano ao redor de categorias que emergiram de estudos prévios identificados na literatura. A escolha pela categoria diagnóstico como ponto de interesse se deu por meio de insumos extraídos do texto de Souza e Ferreira (2011). As autoras, apesar de não analisarem diretamente o diagnóstico do PNT 2003-2007, acabaram por traçar um paralelo entre os gargalos identificados, os objetivos e as metas descritas no instrumento.

Moya e Dias (2008), por sua vez, discorreram sobre os principais elementos do PNT 2007-2010, buscando uma relação com os 08 Objetivos de Desenvolvimento do Milênio (ODM). Da mesma maneira, o objetivo de Kanitz et al. (2010) foi discutir os macroprogramas do PNT 2007-2010, considerando três elementos: inclusão, geração de emprego e renda e desenvolvimento local. A partir destes textos, identificou-se a possibilidade de analisar, em uma categoria, o conjunto de intervenções nos demais planos.

1. O PNT 2018-2022 teve sua aprovação publicada em maio de 2019 (Decreto ${ }^{\circ}$ 9.791/19), no âmbito do Governo Bolsonaro. Este trabalho manteve seu foco de análise na primeira versão do plano, publicada em 2018. 
No que se refere aos objetivos, Lemos (2013) oferece uma perspectiva de comparação entre dois Plano Plurianuais (PPA), de 2008-2011 e de 2012-2015, e os PNT do período. Os PPA estabelecem as prioridades de investimento nos programas do governo para quatro anos. Por meio da análise comparativa, o autor identificou que os objetivos, apesar de diversos, se concentravam em projetos de infraestrutura, promoção e apoio à comercialização. Além de ações de apoio à regionalização do turismo. Lemos (2013) também concluiu que houve consonância entre o previsto nos PPA e os objetivos setoriais dos planos nacionais do ciclo analisado.

E, por último, as categorias continuidade e inovação surgiram a partir das inquietações observadas nos textos de Rua (2006) e Rodrigues (2010). Enquanto a primeira autora alerta sobre a fragmentação das políticas públicas brasileiras, o segundo discute sobre vulnerabilidade destas às decisões das administrações anteriores. Tem-se, então, um paradoxo. Ao passo em que é desejável ter PP continuadas, independente da troca de governos, é preciso que elas também apresentem soluções e inovações para os novos desafios que surgem.

\section{ASPECTOS METODOLÓGICOS}

Este estudo tem caráter exploratório-descritivo, conta com emprego de abordagem qualitativa (Sampieri et al., 2013) e técnica documental (Gil, 2008). A coleta de dados baseou-se em cinco categorias inspiradas na literatura consultada e aplicadas aos planos nacionais de turismo correspondentes ao período de 2003 a 2022, conforme mostra o Quadro 1.

Quadro 1 - Termos operacionais da pesquisa

\begin{tabular}{|l|l|}
\hline Termo & Definições Adotadas \\
\hline Diagnóstico & $\begin{array}{l}\text { Evidências dos gargalos do turismo e possibilite uma análise detalhada da } \\
\text { evolução experimentada pelo fenômeno. }\end{array}$ \\
\hline Objetivos & Finalidade que pode ser expressa em objetivos gerais e específicos. \\
\hline $\begin{array}{l}\text { Conjunto de } \\
\text { Intervenções }\end{array}$ & $\begin{array}{l}\text { Desdobramento dos objetivos e das metas, representado por macro } \\
\text { programas ou programas ou o maior nível de agregação das ações previstas. } \\
\text { Orientado em prol da resolução dos gargalos e do alcance dos objetivos e do } \\
\text { previsto nos cenários. }\end{array}$ \\
\hline Continuidade & $\begin{array}{l}\text { Referências de continuidade ao plano anterior ou se as possíveis alterações } \\
\text { foram fruto de mudanças econômicas ou insucesso das propostas anteriores. }\end{array}$ \\
\hline Inovação & $\begin{array}{l}\text { Inovação para o Conjunto de Intervenções quando comparado ao anterior. } \\
\text { Fonte - elaboração própria. }\end{array}$ \\
\hline
\end{tabular}

Por fim, a análise de dados foi baseada na técnica de análise de conteúdo (Bardin, 1977). Seguiram-se as fases recomendadas por Bardin (2011): determinação das unidades de análise, definição de categorias de análise, organização de um quadro de dados e interpretação inferencial do conteúdo. Assim como a seleção e leitura "flutuante" do material a fim de determinar as unidades de análise e definir as categorias. Nesse sentido, a leitura deu origem a uma planilha que computou os dados coletados a partir das categorias estabelecidas e que, posteriormente, foi analisada em relação ao tema e ao plano, proporcionando uma visão específica e comparativa. 


\section{RESULTADOS: APRESENTAÇÃo E ANÁLISE}

Tendo como ponto de partida o objetivo principal da pesquisa, os resultados serão apresentados a partir das categorias pré-estabelecidas: Diagnóstico, Objetivos, Conjunto de Intervenções, Continuidade e Inovação.

\section{Diagnóstico}

Tendo como definição operacional que o diagnóstico é um texto específico que evidencie os gargalos do turismo e possibilite uma análise detalhada da evolução experimentada pelo fenômeno, cabe relembrar a crítica de Noia et al. (2007). Os autores consideram o diagnóstico do PNT 2003-2007 como superficial. Além da ausência de dados fundamentais, como o PIB do turismo brasileiro, o texto contraria a lógica de regionalização, na medida em que considera os gargalos do país como um todo.

No PNT 2007-2010, são apresentados os dados econômicos do crescimento do turismo no Brasil e no mundo, os resultados obtidos com a gestão descentralizada iniciada no plano anterior e o desempenho de alguns indicadores. Tais como o fluxo turístico doméstico, a geração de emprego e renda e a entrada de turistas internacionais. Nota-se uma robustez do contexto apresentado, o que embasou a identificação dos problemas do turismo nacional. Entretanto, a lógica deste plano continua sendo a de considerar todo o território nacional e não as regiões turísticas.

Mesmo com as diferenças contextuais entre os dois diagnósticos, foi possível observar como alguns problemas se repetem ou são bastante similares. São eles: ausência ou insuficiência de dados e sistema de informações turísticas; deficiência na qualificação profissional e na qualidade dos serviços; regulamentação inadequada, sobreposição dos dispositivos legais e legislação descolada da evolução do turismo; ausência ou insuficiência na oferta e no acesso ao crédito; e deficiência na infraestrutura geral e de apoio ao turismo.

Esta similaridade dos problemas indica que não foram registrados avanços no saneamento deles, de um período (2003-2007) para o sequente (2007-2010). Fato que carece de uma comprovação empírica, ausente nos documentos consultados. Mas, que seria útil para sinalizar a evolução das políticas públicas do turismo brasileiro.

Os PNT 2013-2016 e 2018-2022 continuam apresentando os grandes números do turismo no país e globalmente, assim como o desempenho em indicadores econômicos. Permanece a análise territorial que considera todo o Brasil e não as regiões turísticas. Contudo, os documentos não trazem claramente quais os problemas identificados e, novamente, se aqueles dos planos anteriores foram sanados ou minimizados.

Tem-se apenas um desafio que se repete nestes dois últimos PNT: os crescentes saldos negativos do turismo na balança de serviços, sendo que em 2017 o valor registrado foi de US\$ 13 bilhões (MTUR, 2018). No plano 2013-2016 são ainda citados: a necessidade de integração institucional, da maior participação do setor privado nas políticas públicas e de prover qualidade para os territórios turísticos. Já no PNT 2018-2022 são citados: a queda do número de turistas 
estrangeiros do segmento de negócios e eventos e o recuo do país no ranking global da International Congress and Convetion Association - ICCA.

Destaca-se que no PNT 2013-2016, na mensagem de abertura do Ministério do Turismo, é informado que o Programa de Regionalização faria um diagnóstico completo das potencialidades e dos problemas das regiões turísticas. No entanto, se este documento foi produzido, ele não integra o PNT 2018-2022. E não foi encontrado nas pesquisas realizadas.

A ausência de um diagnóstico sólido nos quatro planos, colabora para a afirmação de Rua (2006) de que há um descompasso entre as reais necessidades e o planejamento proposto. Uma vez que não se tem clareza sobre os gargalos existentes e se houve evolução na resolução daqueles identificados anteriormente, propor ações assertivas se torna mais difícil.

O descompasso mencionado fica evidenciado na relação dos gargalos apontados nos planos com as metas estabelecidas, como apresentado no Quadro 2. Observase que apenas para 4, dos 11 problemas identificados, pôde-se relacionar as metas propostas. Ou seja, as metas, entendidas como um estado futuro desejado (Marques, 2017), tendem a não contemplar a resolução para todos aqueles que foram considerados como os principais gargalos do turismo brasileiro no período dos PNT.

Outro ponto de atenção é o não alcance da meta relacionada ao fluxo turístico internacional. No PNT 2013-2016, previa-se aumentar para 7,9 milhões a chegada de turistas estrangeiros no país. Entretanto, no PNT 2018-2022, a meta considera que o atual número de chegada de turistas internacionais é de 6,5 milhões. 0 que equivale a 1,4 milhões a menos do que o esperado, evidenciando um desajuste entre o que se pretendia alcançar, o que foi alcançado e o que novamente planejado.

\section{Objetivos}

No que se refere aos objetivos dos planos analisados, identificam-se finalidades comuns nos três primeiros PNT:

- Desenvolver o produto turístico brasileiro com qualidade, contemplando as diversidades regionais, culturais e naturais e aumentar a competitividade;

- Fomentar o turismo nos mercados nacional e internacional;

- Incentivar as viagens domésticas;

- Diversificar a oferta turística; e

- Ampliar e qualificar o mercado de trabalho.

No PNT 2018-2022 não há uma seção para os objetivos. No entanto, na mensagem de apresentação a finalidade principal do plano é expressa como "ordenar as ações do setor público, orientando o esforço do Estado e a utilização dos recursos públicos para o desenvolvimento do turismo" (MTUR, 2018, p. 15). 0 que revela finalidades ainda mais genéricas do que aquelas previstas nos planos anteriores.

Para González (2014), os focos das PPTur mudam ao longo do tempo, o que implicaria também na alteração dos objetivos. Contudo, observa-se que nos PNT alguns destes objetivos, a princípio, têm uma característica de longa duração. Ou até mesmo de rotina, como o fomento ao turismo nos mercados nacional e internacional, a ampliação e qualificação do mercado de trabalho e o incentivo às viagens domésticas. A se pensar consoante a BID (2007, citado por Dias e Matos, 2012) 
e Rua (2006), os demais deveriam ser alcançados e substituídos por novos desafios, buscando-se o equilíbrio entre a continuidade das políticas públicas e a inovação.

Mas, uma vez que não houve alterações expressivas nos objetivos de um PNT para o outro, cabe uma análise crítica se, ao menos, eles apresentam convergência com outros elementos, tais como os diagnósticos e as metas. Conforme explica Marques (2017), os objetivos são propósitos, ou finalidades, que expressam onde se quer chegar a partir do mapeamento dos gargalos (diagnóstico). Já as metas seriam a quantificação deste direcionamento, por meio de tarefas específicas para o alcance dos objetivos. 0 Quadro 2 relaciona os gargalos diagnosticados nos planos com os objetivos e as metas propostas.

Quadro 2 - Análise entre os Gargalos, os Objetivos e as Metas dos PNT

\begin{tabular}{|c|c|c|c|}
\hline PNT & Gargalos & Objetivos & Metas \\
\hline \multirow{5}{*}{$\begin{array}{l}2003-2007 \\
2007-2010\end{array}$} & $\begin{array}{l}\text { Ausência ou } \\
\text { insuficiência de } \\
\text { dados e sistema de } \\
\text { informações turísticas. }\end{array}$ & --- & --- \\
\hline & $\begin{array}{l}\text { Deficiência na } \\
\text { qualificação } \\
\text { profissional e na } \\
\text { qualidade dos serviços. }\end{array}$ & $\begin{array}{l}\text { Ampliar e qualificar o } \\
\text { mercado de trabalho. } \\
\text { Desenvolver o produto } \\
\text { turístico brasileiro } \\
\text { com qualidade, } \\
\text { contemplando as } \\
\text { diversidades regionais, } \\
\text { culturais e naturais }\end{array}$ & $\begin{array}{l}\text { Meta } 5.5 \text { - ampliar a } \\
\text { oferta turística brasileira, } \\
\text { desenvolvendo no mínimo } \\
03 \text { produtos de qualidade } \\
\text { em cada Estado e no Distrito } \\
\text { Federal (PNT 2003-2007) } \\
\text { Meta } 3 \text { - estruturar } 30 \\
\text { destinos turísticos com } \\
\text { padrão de qualidade } \\
\text { internacional até } 2010 \\
\text { (PNT 2007-2010) }\end{array}$ \\
\hline & $\begin{array}{l}\text { Regulamentação } \\
\text { inadequada, } \\
\text { sobreposição dos } \\
\text { dispositivos legais e } \\
\text { legislação descolada da } \\
\text { evolução do turismo. }\end{array}$ & --- & --- \\
\hline & $\begin{array}{l}\text { Ausência ou } \\
\text { insuficiência na oferta } \\
\text { e no acesso ao crédito. }\end{array}$ & $\begin{array}{l}\text { Fomentar o turismo } \\
\text { nos mercados } \\
\text { nacional e } \\
\text { internacional. }\end{array}$ & --- \\
\hline & $\begin{array}{l}\text { Deficiência na } \\
\text { infraestrutura geral e } \\
\text { de apoio ao turismo. }\end{array}$ & --- & $\begin{array}{l}\text { Meta } 3 \text { - estruturar } 30 \\
\text { destinos turísticos com } \\
\text { padrão de qualidade } \\
\text { internacional até } 2010 \\
\text { (PNT 2007-2010) }\end{array}$ \\
\hline
\end{tabular}

(Continua...) 
Quadro 2 - Continuação.

\begin{tabular}{|c|c|c|c|}
\hline PNT & Gargalos & Objetivos & Metas \\
\hline $\begin{array}{l}2013-2016 \\
2018-2022\end{array}$ & $\begin{array}{l}\text { Saldos negativos do } \\
\text { turismo na balança } \\
\text { de serviços. }\end{array}$ & $\begin{array}{l}\text { Incrementar a } \\
\text { geração de divisas e } \\
\text { a chegada de turistas } \\
\text { estrangeiros (PNT } \\
\text { 2013-2016). } \\
\text { Incentivar o brasileiro } \\
\text { a viajar pelo Brasil } \\
\text { (PNT 2013-2016) }\end{array}$ & $\begin{array}{l}\text { Meta } 1 \text { - aumentar para 7,9 } \\
\text { milhões a chegada de turistas } \\
\text { estrangeiros no país } \\
\text { (PNT 2013-2016). } \\
\text { Meta } 2 \text { - aumentar para } \\
\text { US\$ 10,8 milhões a receita } \\
\text { com o turismo internacional } \\
\text { até } 2016 \text { (PNT 2013-2016). } \\
\text { Meta } 1 \text { - aumentar a } \\
\text { entrada anual de turistas } \\
\text { estrangeiros de 6,5 para 12 } \\
\text { milhões (PNT 2018-2022). } \\
\text { Meta } 2 \text { - aumentar a receita } \\
\text { gerada pelos visitantes } \\
\text { internacionais de US\$ 6,5 } \\
\text { para US\$ 19 bilhões } \\
\text { (PNT 2018-2022). }\end{array}$ \\
\hline \multirow{3}{*}{$2013-2016$} & $\begin{array}{l}\text { Necessidade } \\
\text { de integração } \\
\text { institucional. }\end{array}$ & --- & --- \\
\hline & $\begin{array}{l}\text { Maior participação } \\
\text { do setor privado nas } \\
\text { políticas públicas. }\end{array}$ & --- & --- \\
\hline & $\begin{array}{l}\text { Prover qualidade } \\
\text { para os territórios } \\
\text { turísticos. }\end{array}$ & $\begin{array}{l}\text { Melhorar a qualidade } \\
\text { e aumentar a } \\
\text { competitividade do } \\
\text { turismo brasileiro. }\end{array}$ & $\begin{array}{l}\text { Meta } 4 \text { - elevar para } 70 \\
\text { pontos o índice médio de } \\
\text { competitividade turística } \\
\text { nacional até } 2016 .\end{array}$ \\
\hline \multirow[t]{2}{*}{$2018-2022$} & $\begin{array}{l}\text { Queda do número de } \\
\text { turistas estrangeiros } \\
\text { do segmento de } \\
\text { negócios e eventos. }\end{array}$ & 0--- & --- \\
\hline & $\begin{array}{l}\text { Recuo do país no } \\
\text { ranking global da ICCA. }\end{array}$ & --- & --- \\
\hline
\end{tabular}

Fonte - elaboração própria a partir dos Planos Nacionais de Turismo.

A partir dos dados apresentados, conclui-se que não existe um encadeamento claro entre os três elementos para a maioria dos objetivos. A exceção aparece quando o tema é a qualificação profissional, a qualidade dos serviços e dos territórios turísticos e o saldo negativo da balança comercial. Para esses três gargalos há objetivos estabelecidos e também metas propostas.

Nota-se ainda que o objetivo principal do PNT 2018-2022, que é o de ordenar as ações do setor público, teria relação com o gargalo do PNT 2013-2016 sobre a necessidade de integração institucional. Apesar de não estar explícito no plano 2018-2022, entende-se que este desafio permanece, já que ele é a sua principal finalidade. No entanto, não foram previstas metas para esse fim. 


\section{Conjunto de Intervenções}

Dentre as categorias analisadas, o conjunto de intervenções foi a que ensejou uma reflexão mais extensa. Uma vez que ela está sendo considerada como o desdobramento dos objetivos e das metas dos PNT, elementos cruciais para o presente artigo.

Representados por diferentes nomenclaturas - macro programas, programas, ações, iniciativas - os conjuntos de intervenções também receberam distintos graus de detalhamento. Dos planos analisados, aqueles que apresentaram um detalhamento mais completo foram o PNT 2007-2010 e o PNT 2018-2022. 0 primeiro se divide em 08 macro programas e 23 programas. Já o segundo tem uma estrutura mais complexa com: 04 diretrizes desdobradas em 05 linhas estratégicas que se conectam com 17 iniciativas e que, por sua vez, apresentam 44 propostas estratégicas.

Mesmo com nomenclaturas e detalhamentos diferentes, grandes temáticas emergiram da análise dos planos. 0 que levou ao agrupamento, neste artigo, em 5 conjuntos: Ordenamento e Gestão, Infraestrutura/Estruturação dos Destinos Turísticos, Informações Turísticas/Estudos e Monitoramento, Qualificação e Promoção e Apoio à Comercialização.

A partir da análise destas temáticas e da classificação das intervenções em uma delas, observa-se que um escopo amplo de trabalho que pode redundar em pulverização de recursos, bem como na falta de autonomia do MTUR para intervir em áreas fora da circunscrição da pasta do turismo (Hall, 2001; Lohmann \& Panosso Netto, 2008). Desta análise também se nota o papel de coordenação, entendido como a articulação entre as diferentes esferas do governo em prol de objetivos comuns e a orquestração das atividades privadas, como um marcante desafio.

Destaca-se que a temática de Ordenamento e Gestão é aquela que mais concentrou iniciativas, em todos os quatro planos. É possível traçar um paralelo com os papéis do governo descrito por Hall (2001), principalmente os de coordenação, planejamento, legislação e regulamentação do governo. Segundo o autor, o governo "ajuda a modelar a estrutura econômica para a indústria do turismo" (Hall, 2001, p. 184) e quando assume estes papéis ele está preparando as melhores condições possíveis para que o turismo aconteça nos destinos.

No papel de planejamento, o governo assume a responsabilidade de propor diretrizes e materializá-las em planos, lidando novamente com diferentes atores. E no papel de legislação e regulamentação, os conflitos são ainda mais evidentes. Distintas áreas podem legislar sobre temas que impactam o turismo, como o meio ambiente, e sequer considerar o planejamento existente. Há ainda uma corrente que defende que o turismo seja cada vez menos regulamentado (Hall, 2001), o que pode contrariar os interesses públicos. Estas características evidenciam a complexidade dos papéis do governo e se refletem nas iniciativas da temática de Gestão e Ordenamento.

Ressalta-se que, como os planos não fazem referência ao cumprimento do proposto pelos anteriores, é difícil identificar se o conjunto de intervenções está sendo de fato executado e quais os resultados alcançados. Entretanto, ao se analisar sistematicamente os quatro planos, nota-se que alguns conjuntos sempre são propostos. Entre eles são reconhecidos: o fortalecimento da política de descentralização, normatização e certificação do turismo, melhoria da infraestrutura 
turística, aperfeiçoamento do sistema de informações turísticas e do monitoramento, a qualificação profissional e a promoção.

Estes conjuntos de intervenções também coincidem com os gargalos mais recorrentes apontados pelos diferentes planos. Torna-se, então, imprescindível que as versões seguintes dos PNT abordem quais questões foram atacadas e quais os resultados alcançados. Caso contrário, a percepção sobre a evolução do turismo brasileiro fica enviesada pelo empirismo.

\section{Continuidade}

O segundo plano (2007-2010) apresenta um forte compromisso com a continuidade do anterior. Fato que fica evidenciado nos objetivos, no conjunto de intervenções e até mesmo no texto de apresentação. Isso pode ser explicado em função da continuidade do governo federal e pode ser exemplificado por algumas passagens do plano. Tais como: “[...] o Plano Nacional de Turismo 2007/2010 tem o claro objetivo de manter e aperfeiçoar todas as iniciativas que já estavam em curso no Ministério" (MTUR, 2007, p. 7). E “é também um compromisso de continuidade das ações já desenvolvidas pelo Ministério do Turismo e pela Embratur. [...] Além de ser uma garantia de que as ações iniciadas pelo governo federal terão continuidade" (MTUR, 2007, p. 11).

Já o PNT 2013-2016, não expressa tal preocupação. 0 referido documento faz menção específica apenas à continuidade do Programa de Regionalização. Criado no PNT 2003-2006, o Programa teria a responsabilidade de realizar um "diagnóstico completo das potencialidades e dos problemas das regiões turísticas do país [...]" (MTUR, 2013, p. 7). Essa passa a ser uma das diretrizes do plano, demonstrando um fortalecimento do programa.

Há de se destacar que este PNT foi fortemente embasado nas necessidades dos megaeventos esportivos, apesar da proximidade da realização destes. Tal elemento pode ser explicativo para a mudança dos objetivos e até mesmo do conjunto de intervenções proposto. Observa-se ainda que o PNT 2013-2016 informa que as diretrizes apresentadas tiveram como insumo o Documento Referencial 2011/2014 (MTUR, 2013).

Mais uma vez, percebe-se a ausência de menções sobre o que, do conjunto de intervenções dos planos anteriores, foi executado totalmente ou em que estágio estaria. Sem essa informação não é possível refletir se a continuidade seria ou não necessária, ou em que medida deveriam ser perpetuados os esforços na mesma direção para que os indicadores anteriores fossem alcançados.

O PNT 2018-2022 sugere preocupação em imprimir uma nova identidade, evitando se vincular com os planos anteriores. Entretanto, como visto principalmente no conjunto de intervenções, não há rupturas expressivas no que foi proposto. Nota-se que a regionalização permanece como uma diretriz e a gestão descentralizada assume o caráter de iniciativa. Apesar de não ser claramente indicado, houve um esforço por vincular o plano 2018-2022, em sua formulação, com o "+ Turismo", um pacote de medidas lançado em 2017. 


\section{Inovação}

Considerando que o PNT 2003-2007 foi o primeiro a ser implementado, é possível argumentar que ele, em si, é uma inovação para as PPTur do país. Outra inovação observada, foi a mudança proposta para a regionalização do turismo brasileiro. Com o PNT 2003-2007, o PNTM dá lugar ao Programa de Regionalização do Turismo (PRT). No PRT a perspectiva da descentralização prioriza o desenvolvimento turístico no âmbito regional (Sancho \& Irving, 2010; Candiotto \& Bonetti, 2015). Apesar da escala territorial ter sido alterada, alguns elementos permaneceram tais como os critérios facultativos relacionados a existência de conselhos e fundos municipais de turismo.

Passando para o próximo plano (2007-2010), o referido documento apresenta pouca inovação para o conjunto de intervenções. Fato que poderia ser justificado pela busca de continuidade e não de rupturas. Como diversos programas se repetem, seria até mesmo inviável ampliar muito o escopo de atuação, conforme mencionado anteriormente.

Por sua vez, o PNT 2013-2016 propõe novos programas, alguns deles com temáticas mais atuais. Tais como: o incentivo à pesquisa e inovação e à cooperação internacional, a inteligência de dados, não tão explorada na temática de informações turísticas, e a definição de diretrizes para as Organizações Públicas de Turismo (OPT). 0 que leva a crer uma maior abertura para parcerias público-privadas.

Já outros programas propostos, apesar de não serem tão evidenciados nos planos anteriores, como o fomento ao turismo de base comunitária, não trazem um contexto inovador. Existem ainda propostas que contrariam a tendência de menor intervenção governamental defendida por Hall (2001). Como é o caso dos programas que preveem a classificação de serviços e equipamentos turísticos, por exemplo.

No PNT 2018-2022, a iniciativa de incentivo à inovação permanece. E aparece, pela primeira vez nos planos, a intenção de se definir qual será o posicionamento estratégico do Brasil como produto turístico. Outras duas iniciativas de destaque são a vinculação do planejamento turístico ao setor de segurança pública e a proposta de estimular o desenvolvimento de destinos turísticos inteligentes. Refletese que a inovação começa a aparecer com mais força nos dois últimos PNT. No entanto, permanece o desafio de vencer os gargalos recorrentemente mencionados.

Soma-se a isso a necessidade de desenhar políticas públicas adequadas para enfrentar um novo cenário, diante da recente pandemia da COVID-19. As políticas públicas que estão sendo propostas buscam reduzir o contágio, especialmente por meio do isolamento social, ao mesmo tempo em que almejam minimizar os efeitos econômicos da pandemia no turismo (Clemente et al., 2020). Entre os contundentes impactos tem-se a expectativa de queda de $20 \%$ a $30 \%$ nas chegadas de turistas internacionais para 2020, que resultará em um declínio de, aproximadamente, US\$ 300-450 bilhões nas receitas geradas pelo turismo (OMT, 2020). No Brasil, conforme estudo da Fundação Getúlio Vargas (FGV) (2020), estima-se que sejam perdidos R \$ 116,7 milhões no biênio 2020-2021, considerando que as atividades turísticas demorem até 12 meses para se reequilibrarem economicamente. Essas cifras ilustram as dificuldades do turismo, que necessitarão de políticas públicas ajustadas a este cenário. 


\section{CONSIDERAÇÕES FINAIS}

0 presente artigo teve como principal objetivo realizar uma análise crítica acerca dos PNT do Brasil, que compreendem o período de 2003 a 2022. Com isso, buscou-se ofertar uma visão sistemática e embasada em categorias de análise, permitindo uma visão longitudinal. Foram analisados quatro planos nacionais, no período de 2003 a 2022, ou seja, que cobrem quase 20 anos de planejamento para o turismo brasileiro. Foram analisadas as categorias: diagnóstico, objetivos, conjunto de intervenções, continuidade e inovação.

Ficou evidenciado que os planos guardam espaço para melhorias, principalmente no que se refere às etapas iniciais, que são chaves para a definição dos objetivos, das metas e do conjunto de intervenções. Foi possível demonstrar que não existe um encadeamento para a maioria dos objetivos, deixando obscuro quais problemas levantados seriam atendidos. Ressalta-se também a amplitude dos conjuntos de intervenções, principalmente dos dois primeiros PNT. Um escopo amplo de trabalho tende a levar a uma pulverização de recursos, já escassos e com tendências de redução crescente.

A falta de padronização e de definição dos critérios para a escolha dos indicadores dificulta a comparação sobre possíveis avanços ao longo dos anos. Isto, pois, na medida em que o que aparece em um plano, não necessariamente será retomado no seguinte. Assim sendo, a análise sobre a evolução do próprio turismo brasileiro, quando embasada pela leitura dos planos, fica prejudicada.

A continuidade é frágil e não emerge como uma preocupação central na maior parte dos PNT analisados. Foi revelada dificuldade de aferir a evolução dos indicadores a partir da leitura dos documentos. Bem como uma ausência de reflexão sobre a execução das intervenções propostas nos planos anteriores. Por fim, nota-se ainda que os planos também têm uma presença limitada no quesito inovação. Observa-se, contudo, que ela começa a aparecer com mais força nos dois últimos PNT, possivelmente por ser uma questão contemporânea que vem ganhando espaço no setor de turismo. Mas ainda revela-se com uma presença tímida nas políticas públicas federais de turismo brasileiras.

Ao final, essa análise ressalta dois pontos de atenção. 0 primeiro deles é a limitação que os planos apresentam de construírem uma visão de longo prazo e estratégica para o desenvolvimento do turismo brasileiro. Eles tendem a ser compartimentados em gestões de 4 anos e sem aferição de resultados clara ao final, o que limita uma visão sobre os eventuais avanços. 0 segundo aspecto é a dificuldade de equilibrar uma perspectiva de continuidade, necessária para o avanço em longo prazo, ao mesmo tempo em que se busca a inovação em um setor dinâmico como o turismo. Ademais, eles podem ficar obsoletos durante seu período de vigência, como pode ser observado diante do cenário da pandemia de Covid-19, que deverá afetar significativamente o PNT 2018-2022.

Este estudo apresenta limitações ligadas às informações disponíveis nos documentos dos planos. Para trabalhos futuros, sugere-se agregar as eventuais atualizações do plano 2018-2022. Ainda, a fim de refinar a análise dos resultados dos PNT, sugere-se abarcar elementos da execução das proposições e seu monitoramento, bem como seu relacionamento com outras atividades executadas pelo MTUR. Isso poderia ser feito por dados de execução orçamentária, por informações dos sistemas internos de gerenciamento do órgão, ou mesmo a partir de 
entrevistas com gestores e técnicos que participaram do processo de formulação e implementação destes planos, buscando identificar sua eficácia e efetividade. Outra possibilidade de enriquecimento da análise perpassa interpretação das configurações ideológicas presentes nos planos, podendo ser realizada a partir da análise dos discursos.

\section{REFERÊNCIAS}

BARDIN, L. (1977). Análise de Conteúdo. Presses Universitaires de France.

BARDIN, L. (2011). Análise de Discurso. Edições 70.

CANDIOTTO, L. Z. P., \& BONETTI, L. A. (2015). Trajetória das Políticas Públicas de Turismo no Brasil. Revista TURyDES: Turismo y Desarollo Local, 8(19), Artigo ISSN 1988-5261. Recuperado em 12 de junho de 2019, de http://www.eumed.net/rev/turydes/19/ politicas.html

CLEMENTE, A. C. F., DE ANDRADE, L. G., STOPPA, E. A., \& SANTOS, G. E. O. (2020). Políticas Públicas Frente aos Impactos Econômicos da COVID-19 no Turismo. Cenário Revista Interdisciplinar em Turismo e Território, v. 8, n14, 73-85. Recuperado em 10 de março de 2020, de https://periodicos.unb.br/index.php/revistacenario/article/ view/32210/26423.

CRUZ, M. R. de C. (2000). Políticas de Turismo e Território. Contexto.

DIAS, R., \& MATOS, F. (2012). Políticas Públicas: Princípios, Propósitos e Processos. Atlas.

FAYOS-SOLÁ, E.; MORALEDA, L. F., \& MAZÓN, A. I. M. (2012). Elaborando un Plan de Política Turística: consideraciones metodológicas. Papers de Turisme, 51, 41-65. Recuperado em 12 de junho de 2019, de http://www.papersdeturisme.gva.es/ojs/index.php/ Papers/article/view/196.

FUNDAÇÃO GETÚLIO VARGAS (2020). Impactos Econômicos do COVID-19. Propostas para o Turismo Brasileiro. Recuperado em 10 de março 2020, de https://fgvprojetos.fgv.br/ sites/fgvprojetos.fgv.br/files/01.covid19_impactoeconomico_v09_compressed_1.pdf

GELINSKI, C. R. O, \& SEIBEL, E. J. (2008). Formulação de Políticas Públicas: questões metodológicas relevantes. Revista de Ciências Humanas, v. 42, n. 1 e 2, 227-240. Recuperado em 13 de junho de 2019, de https://periodicos.ufsc.br/index.php/ revistacfh/article/view/2178-4582.2008v42n1-2p227

GIL, Antônio Carlos (2008). Como elaborar projetos de pesquisa. São Paulo: Atlas.

GONZÁLEZ, M. V. P. (2014). Gobernanza turística: ¿Políticas públicas innovadoras o retórica banal? Caderno Virtual de Turismo, 14, 9-22. Recuperado em 12 de junho de 2019, de http://www.ivt.coppe.ufrj.br/caderno/index.php/caderno/article/view/1023/408.

HALL, C. M. (2001). Planejamento Turístico. Políticas, processos e relacionamentos. Contexto.

HALL, C. M., \& JENKINS, J. (2004). Tourism and Public Policy. In LEW, A. A., HALL, C. M., \& WILLIAMS, A. M. A Companion to Tourism (pp. 525-540). Blackwell Publishing.

JENKINS, C. L, \& HENRY, B.M (1982). Government Involvement in Tourism in Developing Countries. Annals of Tourism Research, 9(4), 499-521. https://doi.org/10.1016/01607383(82)90070-6

KANITZ, H. G., TRIGUEIRO, R. P. C., ARAÚJO, M. A. D., \& SOUZA, W. J. (2009). Plano Nacional de Turismo 2007/2010: da Análise do Conteúdo aos Desafios da Prática. VI Seminário Anptur, 1-12.

KANITZ, H. G., TRIGUEIRO, R. P. C., \& ARAÚJO, M. A. D. (2010). Perspectivas do Plano Nacional de Turismo 2007/2010: avanços ou utopias? Revista Turismo em Análise, 21(3), 644-667. Recuperado de http://www.revistas.usp.br/rta/article/view/14235/16053. 
KINGDON, J. W. (1995). Agenda, Alternatives, and Public Policies. Addison-Wesley Educational Publisher Inc.

LANZARINI, R. \& BARRETO, M. (2014). Políticas Públicas no Brasil para um Turismo Responsável. Revista Visão e Ação, 16(1), 185-215. 10.14210/rtva.v16n1.p185-215

LEMOS, C. C (2013). Planejamento do turismo em âmbito federal: uma análise dos instrumentos utilizados e do investimento do setor. Revista Administração Pública, 47(6), 1401-1427. Recuperado em 12 de junho de 2019, de http://www.scielo.br/ pdf/rap/v47n6/04.pdf.

LICKORISH, L., \& JENKINS, C. (1996). An Introduction to Tourism. Butterworth Heinemann.

LOHMANN, G., \& PANOSSO NETTO, A. (2008). Teoria do Turismo: conceitos, modelos e sistemas. Aleph.

MANUAL DE OSLO. (2005). Diretrizes para Coleta e Interpretação de Dados sobre Inovação ( $3^{\mathrm{a}}$ ed.). ARTI e FINEP.

MARQUES, J. R. (2018, 12 de novembro). Definição de metas e objetivos. Portal IBC. Recuperado em 05 de dezembro de 2018, de http://www.ibccoaching.com.br/portal/ metas-e-objetivos/definicao-metas-objetivos/

MEI, X. Y, ARCODIA, C., \& RUHANEN, L. (2012). Towards Tourism Innovation: A critical review of public policies at the national level. Tourism Management Perspectives, 4, 92105. Recuperado em 12 de junho de 2019, de https://www.academia.edu/27168596/ Towards_tourism_innovation_A_critical_review_of_public_polices_at_the_national_level

MINISTÉRIO DO TURISMO. (2003). Plano Nacional de Turismo. Diretrizes, Metas e Programas. 2003-2007. Recuperado em 12 de outubro de 2019, de http://www.turismo.gov.br/ publicacoes/item/32-planos-nacionais.html

MINISTÉRIO DO TURISMO. (2007). Plano Nacional de Turismo. 2007/2010. Recuperado em 12 de outubro de 2019, de http://www.turismo.gov.br/publicacoes/item/32planos-nacionais.html

MINISTÉRIO DO TURISMO. (2013). Plano Nacional de Turismo. 0 Turismo fazendo muito mais pelo Brasil. 2013-2016. Recuperado em 12 de outubro de 2019, de http://www. turismo.gov.br/images/pdf/plano_nacional_2013.pdf

MINISTÉRIO DO TURISMO. (2018). Plano Nacional de Turismo. 2018-2022. Mais Emprego e Renda para o Brasil. Recuperado em 12 de outubro de 2019, de http://www.turismo. gov.br/2015-03-09-13-54-27.html

MINISTÉRIO DO TURISMO. (2019). Orientações para Atualização do Mapa do Turismo Brasileiro 2019. Recuperado em 12 de outubro de 2019, de http://regionalizacao. turismo.gov.br/images/conteudo/Doc\%200rientador\%20Mapa\%202019\%20-\%20 APROVADO.pdf

MINISTÉRIO DO TURISMO. (2019b). Plano Nacional de Turismo. Ministério do Turismo. Recuperado em 12 de outubro de 2019, de http://www.turismo.gov.br/2015-0309-13-54-27.html

MOLINA, S., \& RODRÍGUEZ, S. (2001). Planejamento Integral. EDUSC.

MOYA, I. M. S., \& DIAS, C. M. M. (2008). O Plano Nacional de Turismo 2007/2010 e os Objetivos de Desenvolvimento do Milênio: Turismo, Hospitalidade e Cidadania. $V$ Seminário de Pesquisa na América Latina, 1-14. Recuperado em 01 de junho de 2019, de https://www.ucs.br/ucs/tplVSeminTur\%20/eventos/seminarios_semintur/ semin_tur_5/trabalhos/arquivos/gt05-01.pdf

NAIM, M. (2015). O Fim do Poder. Leya.

NASCIMENTO, V.L. Q. (2013). Plano Nacional do Turismo 2003-2007: afinal, o que resultou? VI Encontro Nacional da Anppas, 1-17. Recuperado em 02 de maio de 2019, de http:// www.anppas.org.br/encontro6/anais/ARQUIVOS/GT1-147-222-20120629201931.pdf 
NOIA, A. C, VIEIRA JÚNIOR, A., \& KUSHANO, E. S (2007). Avaliação do Plano Nacional de Turismo: Gestão do Governo Lula, entre os anos de 2003 a 2007. Cultur - Revista de Cultura e Turismo, 01(01), 1-16. Recuperado em 01 de junho de 2019, de http:// periodicos.uesc.br/index.php/cultur/article/view/221

ORGANIZAÇÃO MUNDIAL DO TURISMO (2020). UNTWO: International Tourism Arrivals Could Fall By 20-30\% in 2020. https://webunwto.s3.eu-west-1.amazonaws.com/s3fspublic/2020-03/200327\%20-\%20COVID-19\%20Impact\%20Assessment\%20EN.pdf

PEREIRA, C. A. S (1999). Políticas Públicas no Setor de Turismo. Revista Turismo em Análise, 10(2), 7-21. Recuperado em 01 de junho de 2019,de http://www.revistas.usp.br/rta/ article/view/63477/66221

PIMENTEL, M. P. C., PEREIRA, J. R., PIMENTEL, T. D., \& CARRIERI, A. P. (2011). As cinco vidas da agenda pública brasileira de turismo. Observatório de Inovação do Turismo. Revista Acadêmica, VI(4), 1-25. Recuperado em 01 de junho de 2019, de http:// bibliotecadigital.fgv.br/ojs/index.php/oit/article/view/5803/4515.

RODRIGUES, M. M. A. (2010). Políticas Públicas. PubliFolha.

RUA, M. G (2006). Turismo e Políticas Públicas de Inclusão. In INSTITUTO BRASILEIRO DE ADMINISTRAÇÃO MUNICIPAL - IBAM. Turismo Social: diálogos do Turismo uma Viagem de Inclusão (17-37). IBAM.

SAMPIERI, R. H., COLLADO, C. F., \& LUCIO, M. P. B. (2013). Metodologia de Pesquisa. Penso.

SANCHO, A., \& IRVING, M. A. (2010). Interpretando o Plano Nacional de Turismo 2003/2007 sob a ótica da inclusão social. Caderno Virtual de Turismo, 10(3), 103-120. Recuperado em 13 de junho de 2019, de http://www.ivt.coppe.ufrj.br/caderno/index.php/ caderno/article/view/490/260.

SARAVIA, E. (2006). Introdução à Teoria da Política Pública. In SARAVIA, E.; FERRAREZI, E. (Org.). Políticas Públicas (21-42). ENAP.

SANSOLO, D. G., \& CRUZ, R. C. A. (2003). Plano Nacional de Turismo: uma análise crítica. Caderno Virtual de Turismo, 3(4), 1-6. Recuperado em 13 de junho de 2019, de https:// www.mobilizadores.org.br/wp-content/uploads/2014/05/texto-5363c74540fdc.pdf

SOUZA, C. (2006). Políticas Públicas: Conceitos, Tipologias e Sub-Áreas. Revista Sociologias, 8(16), 20-45. Recuperado em 13 de junho de 2019 de http://www.scielo.br/pdf/ soc/n16/a03n16.

SOUZA, M. J. B., \& FERREIRA, E. (2011). Planos Nacionais de Turismo, Desenvolvimento Local e Sustentabilidade. XXXV Encontro da ANPAD, 1-13. Recuperado em 13 de junho de 2019, de http://www.anpad.org.br/admin/pdf/ESO2544.pdf

Recebido em: 20/06/2019

Aprovado em: 04/04/2020

\section{CONTRIBUIÇÕES}

Graziele Júnia Pereira Vilela: definição do problema de pesquisa e objetivos, desenvolvimento da proposição teórica, realização da revisão bibliográfica e fundamentação teórica, escolha dos procedimentos metodológicos, coleta de dados, análise de dados, elaboração de tabelas, gráficos e figuras, redação e adequação do manuscrito às normas da RTA.

Helena Araújo Costa: definição do problema de pesquisa e objetivos, desenvolvimento da proposição teórica, realização da revisão bibliográfica e fundamentação teórica, escolha dos procedimentos metodológicos, análise de dados, revisão crítica e redação do manuscrito. 